\title{
A system for estimating height and site index of western hemlock in the interior of British Columbia
}

\author{
by Gordon D. Nigh ${ }^{1}$
}

The focus of recent site productivity research in British Columbia has been to develop height-breast height age, growth intercept, and ecosystem-site index models. These models, together with a years-to-breast-height model, form a system for estimating site index and height. This system is described for western hemlock (Tsuga heterophylla (Raf.) Sarg.) in the interior of British Columbia. Forty-four western hemlock stem analysis plots were used in the construction of this system. As there are three models for estimating site index, the appropriate model for a given stand depends largely on the stand condition and the precision of the models. A graph of model precision against breast height age gives some assistance in deciding which model should be used to estimate site index.

Key words: western hemlock, site index, height-age model, growth intercept model, years-to-breast-height model, ecosystemsite index model, model precision

\section{Introduction}

Until recently, the only widely available tools for estimating site index ${ }^{2}$ in British Columbia were height-age models for different species. Site productivity research in B.C. is now focusing on developing two types of models for estimating top height and three types of models for estimating site index. Together, these models form a site index system for estimating top height and site index. The site index system is necessary because the height-breast height age models only give good site index estimates when the top height trees reflect the potential productivity of the site on which they are growing and when the breast height age (bha) of the top height trees are within the range of the model development data. However, the height of many stands in B.C. do not reflect the potential productivity of the site because of suppression, top damage, disease, stem breakage, and other factors. Furthermore, the existing height-bha models were developed with data collected from stands generally under 150 years bha. Since many stands are older than this age, it is necessary to extrapolate the height-bha models to estimate site index. In contrast, the models in the site index system allow site index to be estimated under virtually any stand condition.

${ }^{1}$ Research Branch, British Columbia Ministry of Forests, P.O. Box 9519, Stn. Prov. Govt., Victoria, British Columbia, Canada, V8W 9C2 E-mail: Gordon.Nigh@gems2.gov.B.C.ca

${ }^{2}$ In B.C., site index is top height at the index age of breast height age 50.
L'attention de la recherche récente sur la productivité des stations en Colombie-Britannique a porté sur l'élaboration des modèles hauteur-âge à hauteur de poitrine, taille de la pousse annuelle, et écosystème-indice de la station. Ces modèles, ainsi que le modèle âge à hauteur de poitrine, forment un système permettant l'évaluation de l'indice de la station et de la hauteur. Ce système est décrit dans le cas de la pruche de l'ouest (Tsuga heterophylla (Raf.) Sarg.) de l'intérieur de la Colombie-Britannique. Quarante quatre parcelles-échantillons d'analyse de la tige des pruches ont été utilisées pour l'élaboration de ce système. Puisqu'il y a trois modèles pour l'estimation de l'indice de la station, le modèle approprié pour un peuplement donné dépend en grande partie de l'état du peuplement et de la précision des modèles. Un graphique de la précision des modèles en fonction de l'âge à la hauteur de poitrine permet jusqu'à un certain point de déterminer quel modèle pourrait utiliser pour estimer l'indice de la station.

Mots clés: pruche de l'ouest, indice de la station, modèle hauteurâge, modèle de la taille de la pousse annuelle, modèle âge à hauteur de poitrine, modèle écosystème-indice de la station, précision des modèles
The site index system provides estimates of top height from the height-bha models in conjunction with the years-tobreast-height models. Height-bha models express top height as a function of bha and site index. Years-to-breast-height functions estimate the number of years it takes trees to grow to bha zero.

Site index estimates are obtained from the site index system with either the height-bha, growth intercept, or ecosystem-site index models. Height-bha models can be used to estimate site index from height and bha as well as to estimate height (Wang and Payandeh 1993). They perform best near the index age when estimating site index (Nigh and Sit 1996). Therefore, caution should be exercised when these models are used to estimate site index in old-growth and juvenile stands, and they cannot be used in stands that are barren of trees or have trees that are below breast height $(1.3 \mathrm{~m})$. Growth intercept models estimate site index from early height growth. They are designed specifically for estimating site index in juvenile stands that have surpassed breast height (Brown and Stires 1981, Bottenfield and Reed 1988, Avery and Burkhart 1994). Ecosystem-site index models allow site index to be estimated from ecological information such as soil moisture and nutrient regimes (Green et al. 1989, Klinka and Carter 1990, Wang et al. 1994). These models do not require trees with specific characteristics to make site index estimates and consequently they work in situations where direct estimation of site index is not possible (Carmean 1975). None of the models in 
the site index system has been developed specifically for western hemlock in the interior of B.C.

Western hemlock (Tsuga heterophylla (Raf.) Sarg.) is found mainly in the wetter, low- to mid-elevation region in both southeastern and west central B.C. (Meidinger and Pojar 1991). This region is the second-most productive region in Canada, with the wet, low- to mid-elevation region in coastal B.C. being the most productive. These two regions share many ecological features and they are the only regions in B.C. with substantial amounts of western hemlock.

The similarity in the two regions where western hemlock grows led to the coastal western hemlock height-bha and years-to-breast-height models developed by Wiley (1978) to be used in the interior of B.C. These models are based on data from coastal areas of Oregon, Washington, and B.C. Growth intercept models for coastal western hemlock are available (Nigh 1996). Western hemlock ecosystem-site index models are not widely available in the interior of B.C., but some research has been published in this area for coastal western hemlock (Kayahara and Pearson 1996). Unique models should be developed for interior western hemlock despite the similarities between the coastal and interior ecosystems and the availability of coastal models because different height growth patterns are expected. For example, the height estimates from the coastal western hemlock height-bha models are too high for interior conditions for a given level of site index.

A brief description of B.C.'s biogeoclimatic ecosystem classification system is given here, as the nomenclature in the system is used throughout this article. Biogeoclimatic zones are relatively extensive areas with broad, homogeneous macroclimates. Zones are typically named after the dominant climax species in zonal ecosystems, which are ecosystems that are characteristic of the regional climate. Zones are subdivided into subzones which have similar regional climates. Subzone codes are two letters, the first representing precipitation regime ( $\mathrm{x}$ - very dry, $\mathrm{d}$ - dry, $\mathrm{m}$ - moist, $\mathrm{w}$ - wet, $\mathrm{v}$ - very wet) and the second representing temperature regime (in the interior of B.C., h - hot, w - warm, $\mathrm{m}$ - mild, $\mathrm{k}$ - cool, c - cold, v - very cold). Variants reflect further differences in regional climate, for example, areas that are slightly drier, wetter, snowier, warmer, or colder than other areas within a subzone. Variants are numbered consecutively within a subzone from south to north. At the site level, the soil moisture regime and soil nutrient regime are classified. The moisture regimes are very dry, moderately dry, slightly dry, fresh, moist, very moist, and wet. The nutrient regimes are very poor, poor, medium, rich, and very rich.

This report describes the development of a system for estimating the height and site index of western hemlock stands in the Interior Cedar-Hemlock (ICH) biogeoclimatic zone of B.C. This system consists of a height-bha model, a years-to-breastheight model, a growth intercept model, and model relating ecosystem characteristics and site index. It provides a means for estimating western hemlock site index and stand height under many stand conditions. The models themselves are based on previously published technology. Amalgamating these models into a system is an important innovation and is the essence of this report. Having several models that predict site index raises the issue of what model should be used in what situation. This issue is addressed by identifying the conditions under which each model is best suited.

\section{Data and Methods}

The data for this study consist of 44 sample plots located throughout the ICH biogeoclimatic zone of B.C. The plots were established in accordance with the recommended procedures in B.C. (Forest Productivity Councils of British Columbia 1996). Twenty-one plots were in the west central part of the ICH and the remaining 23 plots were located in the southeastern part. The plots were circular, 0.0363 ha in size, and were located in areas that were ecologically homogeneous and predominantly western hemlock. The 0.0363 ha plot size is standard in B.C. for site index research and was chosen to make estimates of top height consistent across different plot sizes used in different applications. The problem of bias in top height estimates from plots with different sizes is discussed by Rennolls (1978). Stands older than 80 years bha were targeted for sampling. Stands in the ICH zone often have a mixture of species, particularly in the southeastern part, which makes it difficult to find predominantly western hemlock stands. Therefore, the condition that the stands be predominantly western hemlock was a target rather than a requirement; some plots had less than $50 \%$ western hemlock. Within each plot, the three largest diameter western hemlock trees were chosen as sample trees. The selected trees were checked for suppression above breast height, damage by biotic and abiotic factors, and bha. Plots with damaged or suppressed sample trees, or with sample trees that have a bha range greater than 20 years, were not sampled. A full ecosystem description of each plot was done (Luttmerding et al. 1990) by identifying each plot's biogeoclimatic zone, subzone/variant, and soil moisture and nutrient regime. Zones and subzone/variants can be identified from maps, vegetation, and elevation. Soil moisture and nutrient regimes are determined from site, soil, and vegetation characteristics.

The sample trees were cut down and sections from the stem were taken at stump height $(0.3 \mathrm{~m})$, breast height, and at 19 additional intervals chosen so that the stem was sectioned into 20 parts of equal length above breast height. The annual growth rings were counted at each section. Sectioning the stem into 20 parts allows the early height growth to be accurately re-constructed, which is necessary for the growth intercept models.

The section height-ring count data were converted into height-bha data and corrected for stem analysis bias which results because the tree sectioning does not always occur at an annual node (Carmean 1972, Newberry 1991). Linear interpolation was done between the sectioning points to obtain annual tree height estimates. Tree height at bha one is the height of the first annual node above breast height. The individual tree data were screened for inappropriate sample trees by graphically assessing their height growth for suppression or damage between bha zero and the index age of 50 years. Trees that were deemed to be inappropriate were deleted from the analysis because suppression or damage in this age range biases the plot's site index. Deleting a tree does not necessarily bias the results since any one of the three trees could have been deleted. It does increase the within-plot variation, but this increase is acceptable given that stem analysis data is too costly to discard whole plots when only one tree is unsatisfactory. All plots had either two or three sample trees after this screening. The heights of the sample trees in each plot were averaged for each bha to obtain top height by bha data. The site index of the plot is the top height at bha 50 . Since the site index is measured rather than estimated, it 
is invariant with respect to the age of the plot since the height growth that occurs after the index age has been reached does not affect the site index.

Four models were analyzed and developed: years-to-breastheight, height-bha, growth intercept, and ecosystem-site index. The analysis of each model is described separately.

\section{Years-To-Breast-Height Model}

Six plots had height growth below breast height that was indicative of prolonged suppression. Since this is uncharacteristic of free-growing managed stands, these plots were deleted from the years-to-breast-height analysis. The height growth between stump and breast height was extrapolated backwards to obtain the number of years it took each tree to reach stump height and breast height.

Equation (1) was fitted to the years-to-breast-height data using nonlinear least squares regression.

$$
\mathrm{YTBH}_{\mathrm{i}}=\mathrm{b}_{0} \times \mathrm{SI}_{\mathrm{i}}^{\mathrm{b}_{1}}+\varepsilon_{\mathrm{i}}
$$

where: $\mathrm{YTBH}_{\mathrm{i}}=$ number of years it took plot $\mathrm{i}$ to reach bha zero from germination,

$\mathrm{SI}_{\mathrm{i}}=$ site index (m) of plot $\mathrm{i}$,

$\mathrm{b}_{0}, \mathrm{~b}_{1}$ are model parameters, and

$\varepsilon_{\mathrm{i}}=$ error term for plot $\mathrm{i}$.

The observed residuals from the fitting of the model were tested for bias, normality, and homoscedasticity using a t-test, Shapiro and Wilk's W test (Shapiro and Wilk 1965), and Endrenyi and Kwong's $F_{\mathrm{k}}$ test (Endrenyi and Kwong 1981), respectively. Residual plots were also used in assessing the fitted model. Independence in the residuals cannot be tested and cannot be ensured because the sampling was not random. All statistical tests for this model, and the other models, were carried out at the $95 \%$ significance level.

\section{Height-bha Model}

Three plots had height growth patterns above bha 50 that are characteristic of damaged trees. The data above bha 50 for these plots were deleted. Five height functions were then fit to the individual plot data: modified Weibull, ChapmanRichard's, logistic, Gompertz, and log-logistic (Thrower et al. 1991, Thrower and Goudie 1992, Sit and Poulin-Costello 1994). The log-logistic was chosen for further analysis as a heightbha model because it had the lowest mean squared error averaged over all the plots.

The log-logistic function was conditioned to go through the site index at the index age (equation 2). A subset of height-bha data from each plot was taken by selecting data at five-year intervals starting at bha five. The subset was taken because annual data are not required to define the height growth pattern for each plot. Height-bha data at bha 50 were excluded because the conditioning of the model made them redundant. The model was then fit to the data using nonlinear least squares regression.

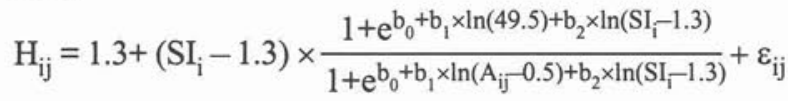

where: $H_{i j}=$ top height $(m)$ of plot $i$ at bha $A_{i j}$, $A_{i j}=$ bha (years) of observation $j$ in plot $i$, $\mathrm{b}_{0}, \mathrm{~b}_{1}$, and $\mathrm{b}_{2}$ are model parameters, and $\varepsilon_{\mathrm{ij}}=$ error term for observation $\mathrm{j}$ in plot $\mathrm{i}$.
The residuals from the fitted model were used to assess the regression assumptions. They were tested for bias, normality, and homoscedasticity using a t-test, the W statistic, and residual plots, respectively. The errors are not independent because multiple observations were taken from each plot. Also, the conditioning of the model often results in heteroscedastic residuals. Heteroscedasticity and lack of independence usually become apparent when plotting the residuals (Nigh and Sit 1996).

\section{Growth Intercept Model}

The growth intercept modelling technique developed by Nigh (1996) is better suited for species that do not have distinct annual branch whorls, such as western hemlock, and is the technique used in this study. This method calculates the growth intercept, or average annual height growth immediately above breast height, from the total height and bha of the trees (equation 3). The relationship between the growth intercept and site index (equation 4) depends on the bha of the trees so different model parameters are required for each bha. Models were developed for bha's one to 50 .

$$
\begin{aligned}
& \mathrm{GI}_{\mathrm{i}, \mathrm{A}}=\frac{\mathrm{H}_{\mathrm{i}, \mathrm{A}}-1.3}{\mathrm{~A}-\mathrm{A}_{\mathrm{i}, \mathrm{l}}} \times 100, \\
& \mathrm{SI}_{\mathrm{i}}=1.3+\mathrm{b}_{1} \times \mathrm{GI}_{\mathrm{i}, \mathrm{A}}^{\mathrm{b}_{2}}+\varepsilon_{\mathrm{i}, \mathrm{A}}
\end{aligned}
$$

where: $\mathrm{GI}_{\mathrm{i}, \mathrm{A}}=$ growth intercept $(\mathrm{cm} / \mathrm{yr})$ for plot $\mathrm{i}$ at bha $\mathrm{A}$ $=1,2, \ldots, 50$ (yrs),

$A_{i, 1}=$ proportion of growing season between bha zero and one when the height of plot $i$ was below breast height,

$$
=\frac{1.3-\mathrm{H}_{\mathrm{i}, 0}}{\mathrm{H}_{\mathrm{i}, 1}-\mathrm{H}_{\mathrm{i}, 0}},
$$

$\mathrm{H}_{\mathrm{i}, \mathrm{A}}=$ top height (m) of plot $\mathrm{i}$ at bha $\mathrm{A}$,

$\mathrm{b}_{1}, \mathrm{~b}_{2}=$ model parameters, and

$\varepsilon_{\mathrm{i}, \mathrm{A}}=$ error term for plot $\mathrm{i}$ at bha $\mathrm{A}$.

To reduce its nonlinear behaviour, parameter $b_{1}$ was transformed so that it appeared in the model as $\mathrm{e}^{\mathrm{b}_{1}}$ (Ratkowsky 1983). Nonlinear least squares regression was used to fit the model and tests for bias, normality, and homoscedasticity were done on the residuals.

\section{Ecosystem-Site Index Models}

Site index can be estimated from soil properties, and often with topographic and climatic data as well, with soil-site models (Clutter et al. 1983, p. 43). Ecosystem-site index models are similar to soil-site models. Site index can be related to biogeoclimatic zone/subzone/variant because these variables represent climatic conditions that impact site productivity, but site index can vary substantially within a zone/subzone/variant. Therefore, ecosystem-site index models should be developed with actual soil moisture regime and/or soil nutrient regime as the predictor variables. Several models were fitted to the data with site index as the dependent variable and various combinations of subzone/variant, actual soil moisture regime, and soil nutrient regime as the independent variables. All models were analyzed as completely randomized designs in an analysis of variance. 


\section{Model Comparison}

The best site index estimate is the one that is most precise, i.e., the one with the smallest standard deviation of the errors. Therefore, the standard deviations of the errors from the models were compared to determine which model gives the best site index estimates. The comparison of the models should be made with an independent set of stem analysis data. However, these data are not available so the comparison was made with the model development data. The standard deviations of the ecosystem-site index and growth intercept models are obtained from the analyses of these models. The standard deviations of the errors in the site index estimates from the height-bha model were obtained by predicting site index from the height-bha model, calculating the error in the predictions, and then applying the formula for the standard deviation to the errors for all bha's up to 150 years.

\section{Results}

The results of the analyses are presented separately for each model.

\section{Years-To-Breast-Height Model}

The fitted years-to-breast-height model is given in equation (5). Table 1 presents the parameter estimates, their asymptotic standard errors, and the root mean squared error of the model. The residuals are unbiased, normally distributed, and homoscedastic. Figure 1 shows this model overlaid on the data points used in its development. One highly influential point with a site index of around $5 \mathrm{~m}$ is obvious.

$$
\mathrm{YTBH}=446.6 \times \mathrm{SI}^{-1.432}
$$

\section{Height-bha Model}

The fitted height-bha model is given in equation (6) and the results of the analysis are in Table 2. The testing of the residuals shows that they are unbiased, but there is evidence that they are not normally distributed or homoscedastic. These violations of the regression assumptions, and the violation of the independence assumption, do not bias the parameter estimates, only the covariance matrix (West et al. 1984, Sen and Srivastava 1990). Therefore, the model can be used for prediction but inferences based on the standard errors of the parameter estimates or the residual variance are unreliable.

$\mathrm{H}=1.3+(\mathrm{SI}-1.3) \times \frac{1+\mathrm{e}^{8.998-1.434 \times \ln (49.5)-1.051 \times \ln (\mathrm{S}-1.3)}}{1+\mathrm{e}^{8.998-1.434 \times \ln (\mathrm{A}-0.5)-1.051 \times \ln (\mathrm{S}-1.3)}(6)}$

Figure 2 is a graph of this model showing height estimates by site index and bha.

\section{Growth Intercept Model}

The growth intercept modelling resulted in one equation for each bha between one and 50. Table 3 shows the parameter estimates, their asymptotic standard error, and the root mean squared error for bha's $5,10,20,30,40$, and 50 . The model overlaid on the data points for these bha's are shown in Figure 3 . There are clear trends in the parameter estimates and the root mean squared error as bha increases. Results not presented in the table or figure can be roughly interpolated, or details can be obtained from the author. The statistical assumptions associated with the models were met as the residual analysis did not reveal any bias, non-normality, or heteroscedasticity.

\begin{tabular}{lcc}
\hline \multicolumn{4}{l}{ Table 1. Results of the years-to-breast-height model analysis } \\
\hline Parameter & Estimate & Standard error \\
\hline $\mathrm{b}_{0}$ & 446.6 & 100.8 \\
$\mathrm{~b}_{1}$ & -1.432 & 0.09327 \\
\hline
\end{tabular}

Root mean squared error: 2.819

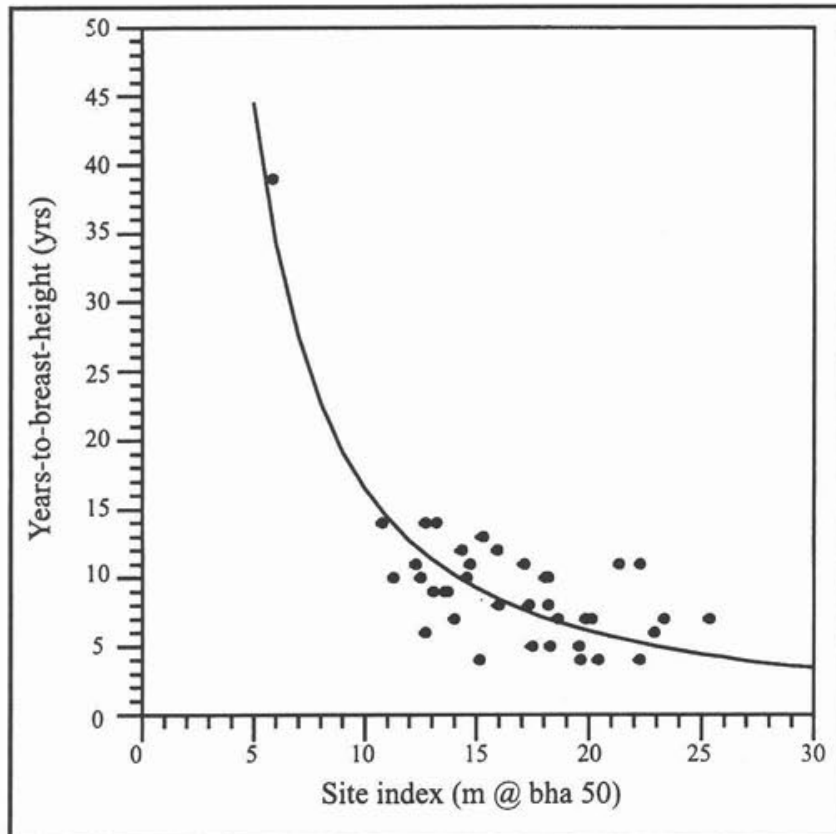

Fig. 1. Years-to-breast-height model ( $\longrightarrow$ ) overlaid on the data points $(\bullet)$.

\section{Ecosystem-Site Index Models}

Models (7) and (8) emerged as superior for estimating site index. Table 4 presents the results of the analysis of the two models. The residuals are normally distributed and homoscedastic.

$$
\begin{aligned}
\mathrm{SI}= & 13.55-6.41 \times \mathrm{mc} 1-7.11 \times \mathrm{mcla}-0.28 \times \mathrm{mc} 2+3.49 \\
& \times \mathrm{mw} 2+2.69 \times \mathrm{mw} 3+0.00 \times \mathrm{wk} 1+4.21 \times \mathrm{F}+4.12 \\
& \times \mathrm{M}+0.00 \times \mathrm{SD} \\
\mathrm{SI}= & 20.00-5.27 \times \mathrm{B}-3.01 \times \mathrm{C}+0.00 \times \mathrm{D}
\end{aligned}
$$

where: $\mathrm{mc} 1, \mathrm{mcla}, \mathrm{mc} 2, \mathrm{mw} 2, \mathrm{mw} 3$, or $\mathrm{wk} 1=1$ if the observation is from the ICH

$\mathrm{mc1}$, mcla, mc2, mw2, mw3, or wk1 subzone/variant, respectively, 0 otherwise,

$\mathrm{F}, \mathrm{M}$, or $\mathrm{SD}=1$ if the actual soil moisture regime of the observation is fresh, moist, or slightly dry, respectively, 0 otherwise, and

$\mathrm{B}, \mathrm{C}$, or $\mathrm{D}=1$ if the soil nutrient regime of the observation is poor, medium, or rich, respectively, 0 otherwise.

\section{Model Comparison}

The standard deviation of the four models (both ecosystemsite index models were evaluated) were plotted against bha (Figure 4). 


\begin{tabular}{lcc}
\hline \multicolumn{3}{l}{ Table 2. Results of the height-bha model analysis } \\
\hline Parameter & Estimate & Standard error \\
\hline $\mathrm{b}_{0}$ & 8.998 & 0.06582 \\
$\mathrm{~b}_{1}$ & -1.434 & 0.01667 \\
$\mathrm{~b}_{2}$ & -1.051 & 0.02090 \\
\hline
\end{tabular}

Root mean squared error: 0.9404

\section{Discussion}

This research results in a system for estimating site index and height for interior western hemlock in B.C. It consists of four models: a height-bha, years-to-breast-height, growth intercept, and ecosystem-site index model. Creating four models from one data set is an efficient use of expensive data. Previously, stem analysis data were often collected for a single purpose, usually to develop a height-bha or growth intercept model.

\section{Limitations}

The focus of the site index system is on the height growth of trees that are expressing the potential productivity of a site. Many trees are not expressing the potential of the site. This causes problems and limitations in both collecting the data to develop the models and in applying the models. Many natural stands have been affected by non-site factors and hence the trees in these stands are not suitable for this type of research. However, the sampling took place primarily in natural stands because managed stands are not yet over bha 50 (they must be at least bha 50 in order for the site index to be known). This age pattern made locating suitable sample plots difficult. Second growth stands under current management regimes should be expressing their potential productivity more so than natural stands, so the height-bha, growth intercept, and years-tobreast-height models are better suited to these stands. However, there will still be some managed stands to which these models should not be applied. The ecosystem-site index models can be used in any stand because they do not rely on the presence of suitable sample trees. Since site index is a measure of a potential and is a site characteristic, the site index concept applies to a stand even when the trees in the stand are not reaching their potential. However, the height-bha models will not adequately represent the height growth pattern when the trees are not growing at their potential. The site index system, with the exception of the ecosystem-site index model, may give biased height and site index estimates when applied in stands that are not meeting their height growth potential.

\section{The Models}

The years-to-breast-height model (equation 5) is an exponential function that estimates the number of years it takes top

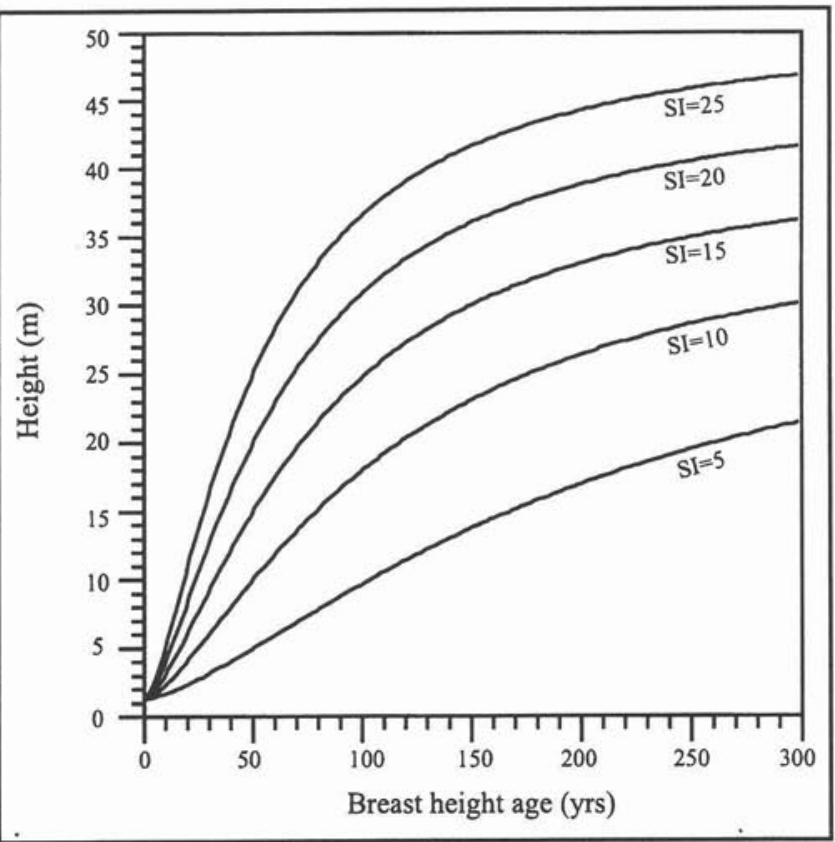

Fig. 2. Height-bha model $(\longrightarrow)$ for site indices $5,10,15,20$, and $25 \mathrm{~m}$.

height trees to reach bha zero from germination. The observation with the lowest site index in the years-to-breast-height data is influential and the remaining data points indicate that a linear model may be more appropriate (Figure 1). This influential observation causes the fitted exponential model to return large years-to-breast-height estimates for site indices below $10 \mathrm{~m}$. Caution should be exercised in that range. The years-to-breast-height model is used to convert bha to total age and vice versa. Top height estimates can also be obtained from this model by assuming a particular growth pattern, for example linear, between the time of germination and the time the top height trees reach breast height.

The height-bha model (equation 6) is based on the log-logistic function. This function is often superior to many others for height-age modelling (Nigh 1997, Thrower et al. 1991). Height-bha models are often extrapolated beyond the age range of the data, so a good model should provide reasonable extrapolated estimates of height (Nigh 1997). Two common problems associated with extrapolation are that the estimated heights are too high or the height trajectories are improperly crossing. These problems can be detected analytically or graphically (Nigh 1997). Crossing-over will not be a problem in the age range in which equation 6 will be applied. However, the maximum estimated height may be slightly high in older

\begin{tabular}{|c|c|c|c|c|c|c|c|c|c|}
\hline bha & Parameter & Estimate & $\begin{array}{l}\text { Standard } \\
\text { error }\end{array}$ & $\begin{array}{l}\text { Root mean } \\
\text { squared error }\end{array}$ & bha & Parameter & Estimate & $\begin{array}{l}\text { Standard } \\
\text { error }\end{array}$ & $\begin{array}{c}\text { Root mean } \\
\text { squared error }\end{array}$ \\
\hline 5 & $\begin{array}{l}b_{1} \\
b_{2}\end{array}$ & $\begin{array}{l}1.213 \\
0.4708\end{array}$ & $\begin{array}{l}0.3761 \\
0.1139\end{array}$ & 3.673 & 30 & $\begin{array}{l}b_{1} \\
b_{2}\end{array}$ & $\begin{array}{r}-0.2943 \\
0.8860\end{array}$ & $\begin{array}{l}0.1595 \\
0.04520\end{array}$ & 1.243 \\
\hline 10 & $\begin{array}{l}b_{1}^{2} \\
b_{2}\end{array}$ & $\begin{array}{l}1.072 \\
0.5088\end{array}$ & $\begin{array}{l}0.3133 \\
0.09313\end{array}$ & 3.274 & 40 & $\begin{array}{l}b_{1}^{2} \\
b_{2}\end{array}$ & $\begin{array}{r}-0.4341 \\
0.9218\end{array}$ & $\begin{array}{l}0.07354 \\
0.02071\end{array}$ & 0.5632 \\
\hline 20 & $\begin{array}{l}b_{1}^{2} \\
b_{2}\end{array}$ & $\begin{array}{l}0.1969 \\
0.7540\end{array}$ & $\begin{array}{l}0.2297 \\
0.06604\end{array}$ & 2.001 & 50 & $\begin{array}{l}b_{1}^{2} \\
b_{2}\end{array}$ & $\begin{array}{c}-0.7061 \\
1.002\end{array}$ & $\begin{array}{l}0.005899 \\
0.001666\end{array}$ & 0.04202 \\
\hline
\end{tabular}




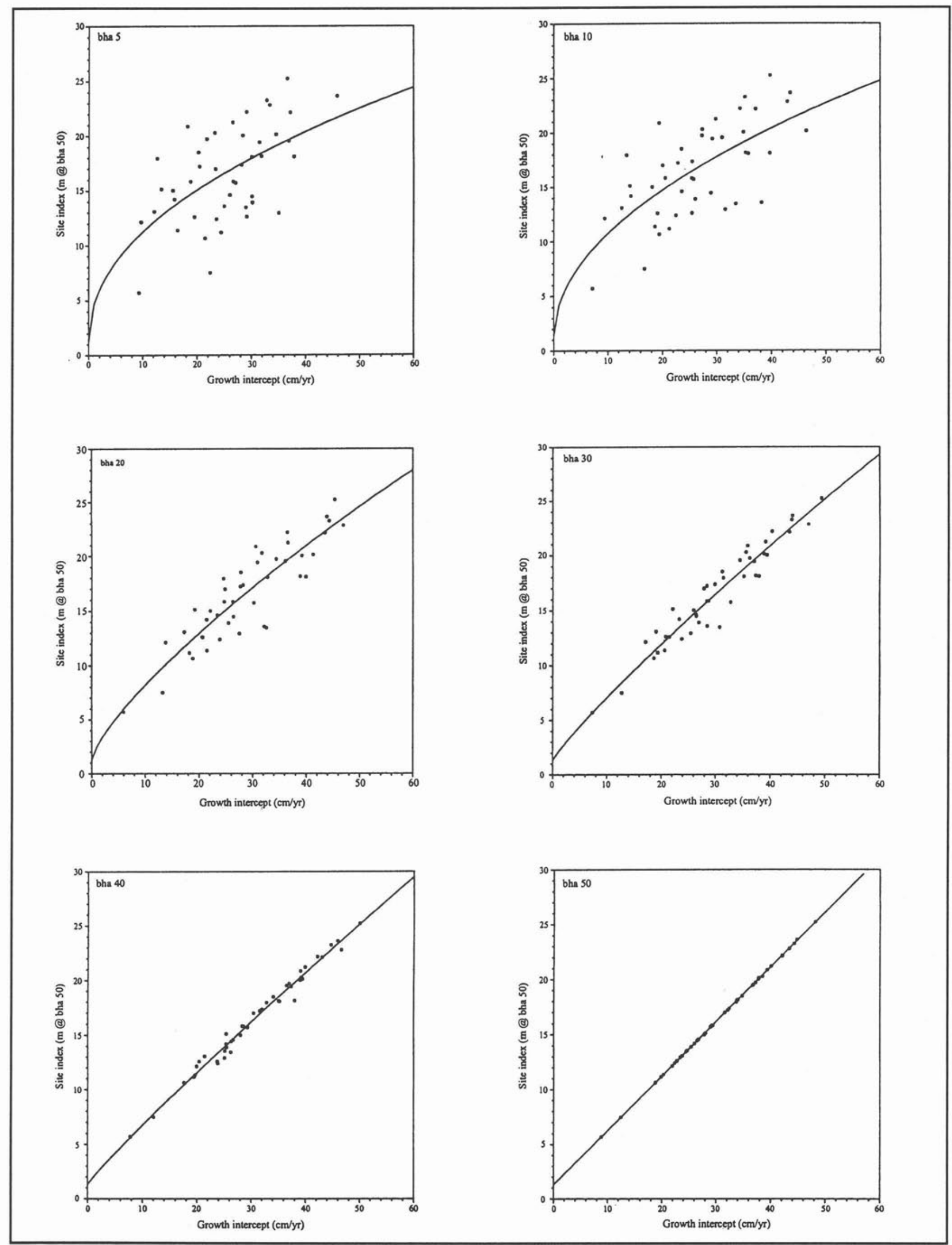

Fig. 3. Growth intercept model (-) overlaid on the data points $(\cdot)$ for breast height ages $5,10,20,30,40$, and 50 . 


\begin{tabular}{|c|c|c|c|c|c|c|c|}
\hline Model & Source of variation & df & Sums of squares & Mean squares & $\mathbf{F}$ & $\mathrm{P}\left(\mathrm{F}>\mathrm{F}_{0.95}\right)$ & $\mathbf{R}^{2}$ \\
\hline 7 & $\begin{array}{l}\text { Subzone/variant } \\
\text { Moisture regime } \\
\text { Error } \\
\text { Total }\end{array}$ & $\begin{array}{r}5 \\
2 \\
36 \\
43\end{array}$ & $\begin{array}{l}367.82 \\
170.11 \\
284.76 \\
822.68\end{array}$ & $\begin{array}{r}73.56 \\
85.05 \\
7.91\end{array}$ & $\begin{array}{r}9.30 \\
10.75\end{array}$ & $\begin{array}{l}0.0001 \\
0.0002\end{array}$ & 0.65 \\
\hline 8 & $\begin{array}{l}\text { Nutrient regime } \\
\text { Error } \\
\text { Total }\end{array}$ & $\begin{array}{r}2 \\
41 \\
43\end{array}$ & $\begin{array}{l}212.06 \\
610.62 \\
822.68\end{array}$ & $\begin{array}{r}106.03 \\
14.89\end{array}$ & 7.12 & 0.0022 & 0.26 \\
\hline
\end{tabular}

stands. This over-estimate can be corrected by collecting data from older stands and re-analyzing the model. However, finding suitable trees in older stands is difficult.

The growth intercept models provide a means of estimating site index in juvenile stands. Their ability to precisely estimate site index deteriorates at younger ages. Therefore, the precision of the site index estimate from the growth intercept models should be considered when scheduling growth intercept surveys. A rough estimate of this precision can be obtained by multiplying the root mean squared error from Table 3 by 2 , which gives an approximate range of the magnitude of the error in the estimated site index that can be expected $95 \%$ of the time. For example, if a forester wants the error in estimated site index to be under $4 \mathrm{~m}$, then a stand should not be surveyed until it is at least 20 years bha.

Two ecosystem-site index models were developed. One estimates site index from biogeoclimatic subzone/variant and actual soil moisture regime (equation 7) and the other model estimates site index from soil nutrient regime alone (equation 8). The former model gives better site index estimates (compare the root mean squared error and $\mathrm{R}^{2}$ statistics in Table 4). However, not all of the ICH subzone/variants can be input into model 7, so its use is limited to the sampled subzone/variants (the ICHmc1, mcla, mc2, mw2, mw3, and wk1). Model 8 is less precise but could be extrapolated to other subzone/variants. In practice, only one of the models would be used to estimate site index.

\section{The Site Index System}

This system contains one model (the height-bha model) to estimate stand height. However, the height-bha, growth intercept, and ecosystem-site index models are available in the system for estimating site index, which creates two issues. Firstly, confusion may arise when more than one model is used to estimate site index because the models will likely give different estimates of site index. Secondly, a practitioner has to decide which model to use to estimate site index. These issues are important and the following discussion will help resolve them.

The site indices derived from these models are estimates, not actual values. While the actual site index is constant, the site index estimates will change from model to model. Also, the site index estimates from the height-bha or growth intercept models will change depending on the bha of the stand. Therefore, foresters need to be aware that the different models will give different site index estimates. The guidelines given below should help foresters select the model that gives the best estimate of site index.

Many factors need to be considered when deciding which model to use to estimate site index. These factors include the

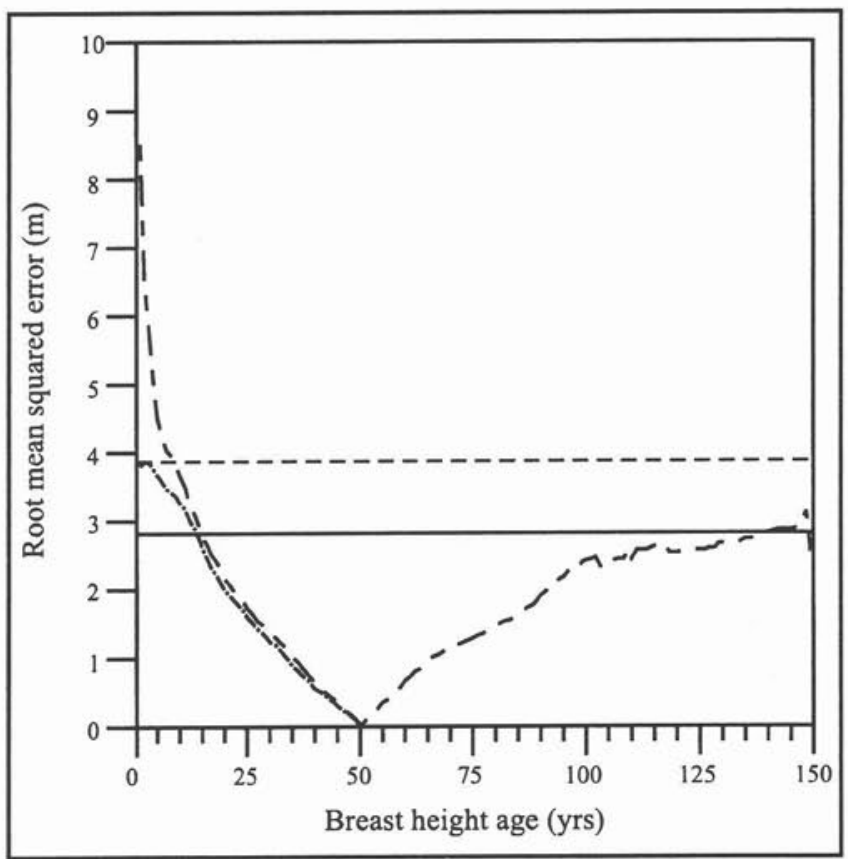

Fig. 4. Graph of model precision against breast height age for the localized ecosystem-site index model ( $\longrightarrow$ ), general ecosystem-site index model (- - ), growth intercept model ( $-\bullet-)$, and heightbha model $(--\longrightarrow)$.

condition of the stand, available data, the resources required to collect the necessary information for the different models, the quality of the data going into the model, and the ability of the surveyors to collect quality data. These factors must be considered on a stand-by-stand basis. If the trees in the stand are not suitable for site index estimation or if the stand is barren of trees, then the only option is to use one of the ecosystemsite index models. However, if the trees are suitable for site index estimation, then the relative precision of the site index estimates from the three models should be considered.

The following conclusions regarding model selection based on model precision are drawn from Figure 4. Site index should be estimated from the localized ecosystem-site index model (equation 7) for stands that are less than 14 years bha. The growth intercept models are used for stands between 14 and 50 years bha, although their precision is only marginally better than the height-bha model's precision. Site index is estimated with the height-bha model for stands between bha 50 and 150 years. For stands older than 150 years bha, the localized ecosystem-site index model again provides the best estimate of site index. The general ecosystem-site index model 
(equation 8) can be used when the localized model is not applicable, but should be restricted to stands that are not yet above breast height. Equation 8 should probably be used in old stands as well, but there is not enough data to determine the bha at which it is more precise than the height-bha model.

I anticipate that this system will be used repeatedly to estimate site index as the stands mature. This would be done to take advantage of the relative precision of the different models. However, this must be done carefully so that a good estimate of site index is not replaced by a poorer estimate. For example, suppose an inventory is done when a stand is 60 years old and the site index is estimated from the height-bha model. Twenty years later when the stand is 80 years old, a new inventory is done and the site index is re-estimated. Here, the first estimate of site index is better than the second estimate (Figure 4). When a re-estimation of site index is being considered, the precision of the existing site index estimate should be compared to the precision of the new site index estimate. Site index should not be re-estimated if the new estimate will be less precise than the old estimate. Figure 4 will help evaluate which estimate of site index is the most precise. In the absence of Figure 4, the following two general guidelines should assist in obtaining the best estimate of site index:

1. For stands between 14 and 150 years bha, site index estimates based on tree height and bha will be better than those based on ecological site characteristics, provided suitable trees are growing in the stand.

2 . Site index estimates based on tree height and bha are better when the stand is closer to the index age of 50 years bha. Guideline number 2, for example, means that a site index estimate taken at bha 40 should be better than a site index estimate taken at bha 65 because the age at which the first estimate was taken is closer to the index age.

\section{Conclusion}

Previously, there were no models available specifically for estimating the height or site index of western hemlock in the interior of B.C.; models developed with coastal data were used instead. The western hemlock site index system, which is comprised of four models (a years-to-breast-height, growth intercept, height-bha, and ecosystem-site index model), overcomes this deficiency. The appropriate model for estimating site index and top height in a given stand depends largely on the stand condition and model precision. This system will give foresters a means of obtaining good site index and height estimates for western hemlock. The methodology can be transferred to other regions, provided a suitable ecosystem classification system is available, and to other species.

\section{Acknowledgements}

Oikos Ecological Services Ltd. collected the data. Bobby Love and Alison Burns (B.C. Ministry of Forests) assisted with the project during the data collection phase. Funding for this project was provided by Forest Renewal B.C. Review comments were provided by Dr. Peter Marshall, University of British Columbia, Peter Ott, and Steve Stearns-Smith, B.C. Ministry of Forests, and two anonymous reviewers.

\section{References}

Avery, T. E. and H. E. Burkhart. 1994. Forest measurements. 4th Ed. McGraw-Hill, Inc. Toronto, ON.
Bottenfield, T. R. and D. D. Reed. 1988. Estimating site quality of young red pine plantations by growth intercept methods. North. J. Appl. For. 5: 91-93.

Brown, J. H. and J. L. Stires. 1981. A modified growth intercept method for predicting site index in young white pine stands. For. Sci. 27: $162-166$.

Carmean, W. H. 1972. Site index curves for upland oaks in the central states. For. Sci. 18: 109-120.

Carmean, W. H. 1975. Forest site quality evaluation in the United States. Adv. Agron. 27: 209-269.

Clutter, J.L., J.C. Fortson, L.V. Pienaar, G.H. Brister, and R.L. Bailey. 1983. Timber management: a quantitative approach. John Wiley \& Sons, Inc. Toronto, ON. 333 p.

Endrenyi, L. and F. H. F. Kwong. 1981. Tests for the behaviour of experimental errors. In L. Endrenyi (ed.) Kinetic Data Analysis. Plenum Press, New York, N.Y.

Forest Productivity Councils of British Columbia. 1996. Minimum standards and stem analysis procedures for site index research. Resource Inv. Br., B.C. Min. For., Victoria, B.C.

Green, R. N., P. L. Marshall, and K. Klinka. 1989. Estimating site index of Douglas-fir (Pseudotsuga menziesii [Mirb.] Franco) from ecological variables in southwestern British Columbia. For. Sci. 33: $50-63$.

Kayahara, G. J. and A. F. Pearson. 1996. Relationships between site index, and soil moisture and nutrient regimes for western hemlock and Sitka spruce. Res. Br., B.C. Min. For., Victoria, B.C. Work. Pap. 17/1996.

Klinka, K. and R. E. Carter. 1990. Relationships between site index and synoptic environmental factors in immature coastal Douglas-fir stands. For. Sci. 36: 815-830.

Luttmerding, H. A., D. A. Demarchi, E. C. Lea, D. V. Meidinger, and T. Vold. 1990. Describing ecosystems in the field. Min. Env. Lands Parks, Victoria, B.C., MOE Manual 11.

Meidinger, D. and J. Pojar. 1991. Ecosystems of British Columbia. Res. Br., B.C. Min. For., Victoria, B.C., Spec. Rep. Ser. 6.

Newberry, J. D. 1991. A note on Carmean's estimate of height from stem analysis data. For. Sci. 37: 368-369.

Nigh, G. D. 1996. Growth intercept models for species without distinct annual branch whorls: western hemlock. Can. J. For. Res. 26: 1407-1415.

Nigh, G. D. 1997. A Sitka spruce height-age model with improved extrapolation properties. For. Chron. 73: 363-369.

Nigh, G. D. and V. Sit. 1996. Validation of forest height-age models. Can. J. For. Res. 26: 810-818.

Ratkowsky, D. A. 1983. Nonlinear regression modeling. Marcel Dekker, Inc., New York, N.Y.

Rennolls, K. 1978. "Top height"; its definition and estimation. Commonw. For. Rev. 57(3): 215-219.

Sen, A. K. and M. S. Srivastava. 1990. Regression analysis theory, methods, and applications. Springer-Verlag New York Inc., New York, N.Y.

Shapiro, S. S. and M. B. Wilk. 1965. An analysis of variance test for normality (complete samples). Biometrika 52(3, 4): 591-611.

Sit, V. and M. Poulin-Costello. 1994. Catalog of curves for curve fitting. Res. Br., B.C. Min. For., Victoria, B.C. Biom. Inf. Handb. 4. Thrower, J. S., A. F. Nussbaum, and C. M. Di Lucca. 1991. Site index curves and tables for British Columbia: Interior species. Res. Br., B.C. Min. For., Victoria, B.C. Land Manage. Handb. Field Guide Insert 6.

Thrower, J. S. and J. W. Goudie. 1992. Estimating dominant height and site index of even-aged interior Douglas-fir in British Columbia. West. J. Appl. For. 7: 20-25.

Wang, Q., G. G. Wang, K. D. Coates, and K. Klinka. 1994. Use of site factors to predict lodgepole pine and interior spruce site index in the Sub-Boreal Spruce zone. Res. Br., B.C. Min. For., Victoria, B.C. Res. Note 114.

Wang, Y. and B. Payandeh. 1993. A numerical method for the solu- 
tion of a base-age-specific site index model. Can. J. For. Res. 23: 2487-2489.

West, P. W., D. A. Ratkowsky, and A. W. Davis. 1984. Problems of hypothesis testing of regressions with multiple measurements from individual sampling units. For. Ecol. Manage. 7: 207-224.
Wiley, K. N. 1978. Site index tables for western hemlock in the Pacific Northwest. Weyerhaeuser For. Pap. No. 17, Western Forestry Research Center, Weyerhaeuser Company, Centralia, WA. 